\title{
Are the anomalous vertebral arteries more hypoplastic?: retrospective linear mixed model approach
}

\author{
Chulho Kim, Jong-Hee Sohn ${ }^{*}$ and Hui-Chul Choi
}

\begin{abstract}
Background: Small or hypoplastic vertebral artery (VA) is one of the risk factor for posterior circulation stroke. We assess whether various types of VA anomaly contribute to its diameter.

Methods: We screened 238 patients who underwent neck $C T$ and MR angiography within 1 month. A V1 anomaly was defined as the abnormal origin of the VA on a three-dimensional MR angiography and a V2 anomaly was defined as the VA not passing through the 6th cervical transverse foramen (TF) on an axial CT image. A linear mixed model was used to evaluate the determinants of VA size.

Results: Among participants, 24 (10.1\%) subjects exhibited an anomalous VA and, of the 476 VAs examined, 11 (2.3\%) had an aortic origin and 27 (5.7\%) had an abnormal entrance into the C6 TF. Presence of the V1 anomaly was positively associated with the $\mathrm{V} 2$ anomaly $(P$ for chi-square $<0.001)$ and a linear mixed model revealed that being male $(0.2 \mathrm{~mm}$ larger, $P=0.015)$, having a right $\mathrm{VA}$ anomaly $(0.3 \mathrm{~mm}$ smaller, $P<0.001)$, having a $\mathrm{V} 1$ anomaly $(0.9 \mathrm{~mm}$ smaller, $P<0.001)$, and having a $\mathrm{V} 2$ anomaly $(0.7 \mathrm{~mm}$ smaller, $P<0.001)$ were significant predictor of VA diameter.

Conclusion: The diameters of VAs with an anomalous aortic origin or an abnormal entrance of the TF were significantly smaller than those of normal VAs. These findings suggest that anomalies of the VA detected in 3-dimensional CTA or MRA may be clues for vertebral artery hypoplasia.
\end{abstract}

Keywords: Vertebral artery, Abnormalities, Computed tomography angiography, Magnetic resonance angiography

\section{Background}

Vertebrobasilar atherosclerosis is a common etiology of posterior circulation strokes (PCS), which account for $20 \%$ of all ischemic strokes [1,2]. Although there is a high prevalence of vertebral artery hypoplasia (VAH) among the normal population [3], VAH also greatly contributes to an increased risk of PCS [3-5]. However, the rates of VAH reported in the literature are quite variable because there is no standard definition for this disorder as of yet [4-8].

During embryological development, the vertebrobasilar artery forms from paired neural arteries that receive their blood supply from carotid-vertebrobasilar anastomoses such as the trigeminal, otic, hypoglossal, and proatlantal arteries $[9,10]$. At the same time, the

\footnotetext{
* Correspondence: deepfoci@hallym.or.kr
Department of Neurology, Chuncheon Sach
Gangwon-do 200-704, Republic of Korea

Department of Neurology, Chuncheon Sacred Heart Hospital, Chuncheon-si,

*Correspondence: deepfoci@hallym.or.kr
Department of Neurology, Chuncheon Sacr
Gangwon-do 200-704, Republic of Korea
}

(c) The Author(s). 2017 Open Access This article is distributed under the terms of the Creative Commons Attribution 4.0 International License (http://creativecommons.org/licenses/by/4.0/), which permits unrestricted use, distribution, and reproduction in any medium, provided you give appropriate credit to the original author(s) and the source, provide a link to the Creative Commons license, and indicate if changes were made. The Creative Commons Public Domain Dedication waiver (http://creativecommons.org/publicdomain/zero/1.0/) applies to the data made available in this article, unless otherwise stated.

longitudinal anastomoses of the cervical intersegmental arteries contribute to the development of the vertebral artery (VA) which, in turn, is connected to the subclavian artery $[11,12]$. The exact nature and precise underlying mechanisms of persistent carotid-vertebrobasilar anastomoses have yet to be fully characterized, but some researchers have suggested that these anastomoses remain unchanged to compensate for the delayed development of the vertebrobasilar artery $[12,13]$. In other words, VAH is the product of the delayed development of the vertebrobasilar artery and might be associated with anomalies in posterior circulation.

It is important to distinguish between acquired narrowing and hypoplasia of the VA because each of these has different atherosclerotic burden. Even in the case of digital subtraction angiography, which is the gold standard method for assessing cerebral arterial pathology, it is difficult to distinguish between atherosclerotic narrowing and 
hypoplasia because it only evaluates internal lumen of the blood vessel. The present study hypothesized that certain vascular anomalies of the VA would be associated with a small or hypoplastic VA. For example, the VA usually arises from the subclavian artery (Fig. 1a) but $2-5 \%$ of all VAs originate directly from the aorta [14-17]. Additionally, the VA typically penetrates the transverse foramen (TF) of sixth cervical vertebra (C6) but approximately $5-10 \%$ of VAs do not pass through this area (Fig. 1b) [17-19]. These anomalies are relatively common, which account for $\sim 5 \%$ of incidence in general $[15,19]$. Thus, the present study aimed to determine whether an anomalous origin of the VA and/or its abnormal penetration of TF other than C6 would contribute to the VA diameter in hospital-based populations.

\section{Methods}

\section{Participants}

The present study was a single-center retrospective observational investigation. Inclusion criteria for this study were a subject who visited our neurology clinic and underwent computed tomography (CT) and magnetic resonance (MR) angiography from January 2012 to December 2015. Additionally, the CT and MR images of each subjects were taken within a 1-month interval ( $n=279$ subjects). We excluded subjects who had motion artifacts on the CT or MR images $(n=12)$, insufficient arterial enhancement on the CT image $(n=23)$, and missing clinical information $(n=4)$. Additionally, patients who had profound vertebral artery tortuosity $(n=2)$ were excluded because vascular tortuosity could affect the radiologic parameter measurement of the VA. Our study is retrospective in nature, therefore, written informed consent was not obtained. However, the design of this study was approved by our Institutional Review Board/Ethics Committee.

\section{Definitions of anatomical variations}

The VA usually originates from the subclavian artery and can be divided into four anatomical parts along the course of craniocervical area [20]. The V1 segment arises from the subclavian artery and extends to the proximal portion of the C6 TF, the V2 (transforaminal) segment extends from the $\mathrm{C} 6$ to the $\mathrm{C} 1 \mathrm{TF}$, the V3 segment extends from the $\mathrm{C} 1$ to the dura, and the V4 segment extends from the dura to the vertebrobasilar junction. In the present study, the anomalous origin of the VA was referred to as a V1 anomaly and consisted of the VA directly originating from the aorta, as shown on a threedimensional MRA (Fig. 1b). A V2 anomaly was defined as a VA that did not pass through the C6 TF (Fig. 1c and d) on an axial source CTA. A window level and a width setting of 400 and 1400 Hounsfield Units, respectively, were selected to optimally visualize the V2 segment anomalies on the CT images.

\section{Measurements of the radiologic parameters}

A 64-section multidetector CT scanner (Somatom Sensation 64, Siemens AG Medical Solutions; Erlangen, Germany) was used to identity V2 segment anomalies using the following settings: $120 \mathrm{kVp}, 100 \mathrm{~mA}$, slice thickness of $1.5 \mathrm{~mm}$, and $512 \times 512$ matrix. All MR imaging

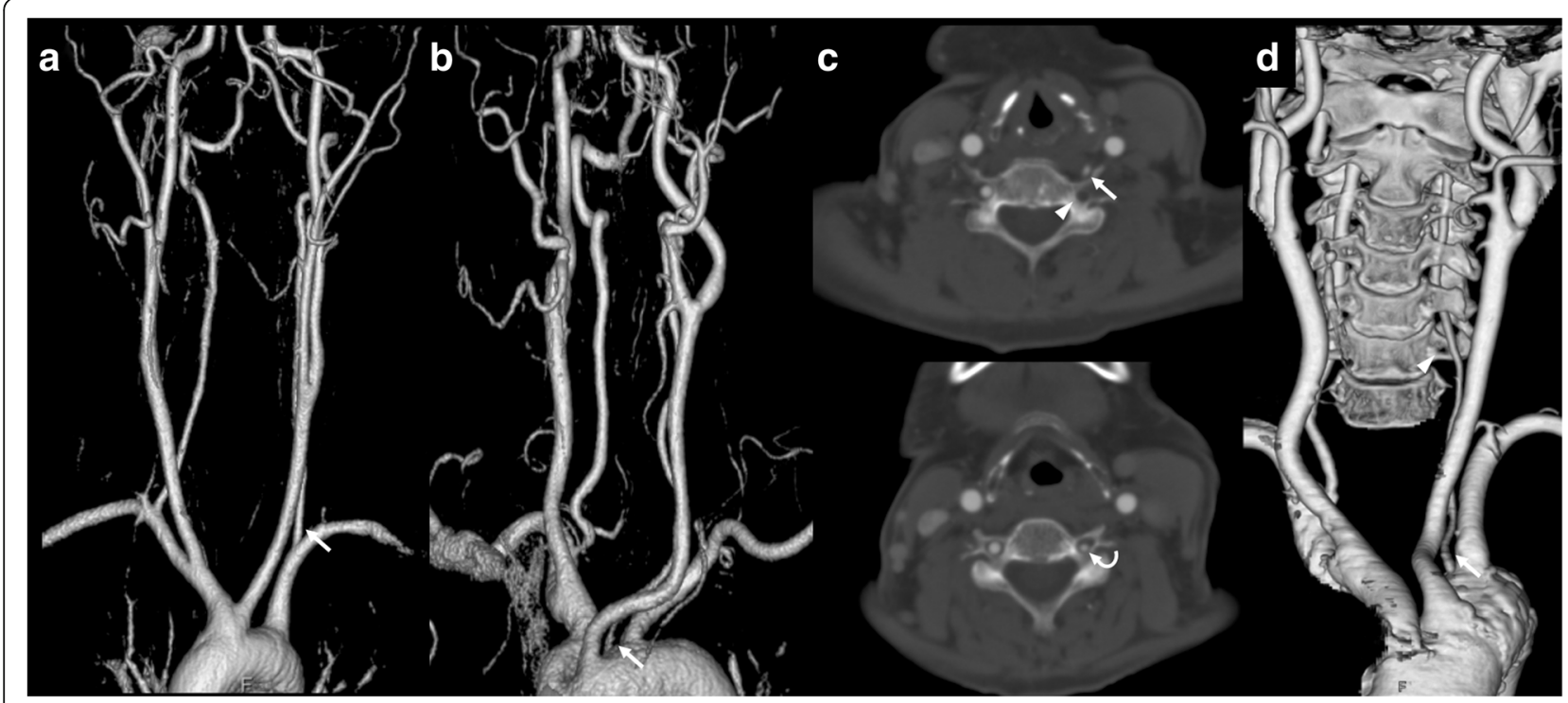

Fig. 1 Left VAs (arrows) originating from (a) the subclavian artery and (b) the aorta on a three-dimensional MR angiography. Axial source images (window level $=400$ Hounsfield Units, width $=1400$ Hounsfield Units) of the CT angiography showing that the left VA (c, arrow) did not penetrate the C6 transverse foramen (arrow head) but that it passed through the C5 transverse foramen (c, curved arrow). Three-dimensional reconstructed CT image (d) showing a left VA (arrow) with an aortic origin and an empty left C6 transverse foramen (arrow head) 
was performed on a $1.5 \mathrm{~T}$ MRI system (Intera, Philips Medical Systems; Best, the Netherlands) with the following settings: slice thickness of $1.3 \mathrm{~mm}, \mathrm{TR}=3.5$, TE $=1.2 \mathrm{~ms}$, field of view $=70 \times 70$, flip angle $=40^{\circ}$, and acquisition matrix $=256 \times 256$. Additionally, real-time MRA was conducted to determine whether there was an anomalous origin of the VA (aortic origin) by administering a dynamic three-dimensional gadolinium injection at a rate of $4 \mathrm{ml} / \mathrm{s}$. The identification of VA anomalies and the measurement of the VA diameters were performed in a pi-view workstation (Infinitt; Seoul, Korea) by two blinded investigators (C Kim and $\mathrm{H}-\mathrm{C}$ Choi) Because there were many cases of stenotic narrowing and vascular tortuosity, which could augment stenotic degree of the VA, the VA diameter was measured at $1 \mathrm{~cm}$ above its origin on the MRA, and defined as the longest diameter perpendicular to the direction of the VA.

\section{Statistical analysis}

These data were freely available from the online (Additional file 1). The baseline characteristics of the patients were summarized using proportions for categorical variables and means \pm standard deviations for numerical data. Descriptive comparisons between the anomalous VA and normal VA groups were assessed using the chisquare test or the Mann-Whitney $U$ test for categorical variables and Student's t-test or paired t-test for continuous variables, as appropriate. The inter-rater reliability of the two blind investigators in terms of the VA diameter measurements was analyzed using the intraclass correlation value and the diameters of the VA were entered into dependent variable. Linear mixed models used to investigate the association of the diameters of the VA with anatomical and demographic characteristics, modeled as fixed effects (including age, sex [female vs. male], the side of the VA (right-sided vs. left-sided; within-subject variable), V1 anomaly [yes vs. no], and V2 anomaly [yes vs. no]). The compound symmetry of the variance-covariance matrix was used for the repeated measure analysis because the variance and correlation (covariance) between the right and the left VAs were constant.

\section{Results}

\section{Patient characteristics}

Of the 238 patients, the mean age ( \pm standard deviation) of the population was $65.9( \pm 12.1)$ years and the proportion of females was $41.6 \%$ ( 99 of 238 patients). Nearly half of the patients (45\%) had experienced an ischemic stroke followed by headaches and/or dizziness with intracerebral hemorrhage (Table 1). Twenty four subjects (10.1\%) exhibited either a V1 (aortic origin) or V2 (abnormal penetration of the TF) anomaly. Patients with an anomalous VA were significantly younger than patients who had a normal VA $(P<0.030)$ but there were no significant differences in terms of gender or comorbid conditions between these two groups.

\section{Anomalies of the VA}

Of the 476 VAs (from 238 patients) that were evaluated in the present study, 11 (2.3\%) had an anomalous origin directly from the aorta and $27(5.7 \%)$ did not have a normal penetration through the C6 TF (Table 2). Of the 11 VAs with an anomalous origin, nine $(81.8 \%)$ had an aortic origin and were preferentially located on the left side. Of the 27 VAs with an abnormal entrance into the C6 $\mathrm{TF}$, there were slightly more on the right side than on the left side (15 vs. 12 , respectively) and the most frequent anomaly was a penetration of the C5 TF in the V2 segment $(n=23,85.2 \%)$ followed by a penetration of the C4 $(n=3,11.1 \%)$ and C3 $(n=1,3.7 \%)$ TF. Additionally, eight of the VAs exhibited anomalies that included both an aortic origin and an abnormal entrance into the C6 TF. An anomalous origin of the VA was associated with an abnormal entrance into the C6 TF (chi-square test, $P<0.001$; Table 3).

\section{Relationships between VA diameter and anomalies of the VA}

The inter-rater correlation coefficient for the measurement of the VA diameter was 0.91 ( $95 \%$ confidence interval $[\mathrm{CI}]: 0.85-0.94, P<0.001)$. The diameters of the VAs with either type of anomaly were significantly smaller than those with a normal morphology (Fig. 2). In the case of a VA with an anomalous origin or an abnormal foraminal entrance, the diameters of the left VAs were significantly smaller than those of the right side. Additionally, eight of the VAs exhibited a combined aortic origin and abnormal foraminal entrance; these were exclusively located on left side and had the smallest diameter of all the measured VAs.

Table 4 illustrates the findings of the linear mixed model analysis regarding the diameters of the VAs. Age did not significantly predict VA diameter but the diameters of the VAs in males were $0.2 \mathrm{~mm}$ larger than those in females $(P=0.015)$ and the diameters of the right VAs were $0.3 \mathrm{~mm}$ smaller than those of the left VAs $(P<0.001)$. Moreover, the diameters of the VAs with either type of anomaly (V1 anomaly, $0.9 \mathrm{~mm}$ smaller, $P<0.001$; V2 anomaly, $0.7 \mathrm{~mm}$ smaller, $P<0.001)$ were considerably smaller than those of normal VAs, respectively. The (anomalous origin)*(abnormal entrance) interaction term was also included in the present linear mixed model but it was not significant. Therefore, this term was removed from the final analysis.

A power analysis with a 0.05 alpha error was performed using the results of the linear mixed model to 
Table 1 Clinical characteristics of the anomalous and non-anomalous VA groups

\begin{tabular}{llll}
\hline & $\begin{array}{l}\text { Total } \\
(n=238)\end{array}$ & $\begin{array}{l}\text { Anomalous } \\
(n=24)\end{array}$ & $\begin{array}{l}\text { Non-anomalous } \\
(n=214)\end{array}$ \\
\hline Female (\%) & $101(42.4 \%)$ & $12(50 \%)$ & $89(41.6 \%)$ \\
Age, years (mean \pm SD) & $65.9( \pm 12.1)$ & $60.8( \pm 12.1)$ & $66.5( \pm 11.9)$ \\
$\begin{array}{l}\text { Comorbidities } \\
\text { Ischemic stroke }\end{array}$ & $107(45.0 \%)$ & $8(33.3 \%)$ & $99(46.3 \%)$ \\
$\quad$ Headache/Dizziness & $42(17.7 \%)$ & $8(33.3 \%)$ & $34(15.9 \%)$ \\
Intracerebral hemorrhage & $31(13.0 \%)$ & $4(16.7 \%)$ & $27(12.6 \%)$ \\
$\quad$ Neoplasm & $30(12.6 \%)$ & $2(8.3 \%)$ & $28(13.1 \%)$ \\
$\quad$ Others & $28(11.7 \%)$ & $2(8.3 \%)$ & $26(12.1 \%)$ \\
V1 anomaly, number $(\%)^{b}$ & $11(2.3 \%)$ & $11(22.9 \%)$ & - \\
V2 anomaly, number $(\%)^{b}$ & $27(5.7 \%)$ & $27(56.3 \%)$ & - \\
\hline
\end{tabular}

SD Standard deviation, V1 anomaly = vertebral artery with an aortic origin; V2 anomaly= vertebral artery with an abnormal entrance to the transverse foramen

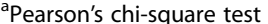

broportions in a total of 476 vertebral arteries

evaluate differences in the diameters of the VAs between the anomalous V2 and normal V2 patients; the diameters of the anomalous VAs and the normal VAs were 2.4 and $3.48 \mathrm{~mm}$, respectively. The actual power for the repeated measures analysis using G*Power 3.1 (Franz Faul, Christian-Albrechts-Universität Kiel; Kiel, Germany) was 0.93 .

\section{Discussion}

In the present retrospective case-control study, the diameters of the VAs of patients with two types of VA anomaly were assessed from an anatomical perspective. A linear mixed model analysis revealed that VA diameter was associated with sex, laterality (right or left), and an anomalous origin and abnormal foraminal entrance of the VAs. Additionally, the prevalence of an anomaly in either the V1 or V2 segment was $10 \%$ (24 of 238 patients), and the diameters of the anomalous VAs were considerably smaller $(\sim 2 \mathrm{~mm})$ than those of normal

Table 2 Incidence of anomalies of the VA according to laterality of the VA

\begin{tabular}{llll}
\hline & Right & Left & Total \\
\hline V1 segment & 236 & 229 & 465 \\
Normal & 2 & 9 & 11 \\
Anomalous & 223 & & \\
V2 segment & 15 & 226 & 449 \\
Normal & 14 & 12 & 27 \\
Anomalous & 1 & 9 & 2 \\
C5 & 0 & 2 & 3 \\
C4 & a & 1 & 1 \\
C3 $^{\text {a }}$ & 0 & & \\
\hline
\end{tabular}

Data are presented as number

${ }^{a}$ VA Entrance to the transverse foramen at each level. For example, C5 represents VAs not passing through $\mathrm{C} 6$ but $\mathrm{C} 5$ transverse foramen
VAs. These findings suggest that V1 and V2 anomalies may be useful marker for small or hypoplastic VA.

Currently, there is a lack of optimal criteria with which to accurately define VAH; there may be several reasons for this. First, VAH is considered to be a clinically benign condition and [21], therefore, digital subtraction angiography cannot be used as a gold standard method of assessment due to the invasiveness of this procedure [22]. Second, previous studies have used various criteria to define VAH in different populations [3-6, 8, 21, 23]. Importantly, as the cutoff value for VAH diameter and the age of the studied population increase, there is an escalating probability of a higher incidence of VAH. Additionally, the definition of hypoplasia includes the meaning 'at birth' and its presence should not change based on the definition of VA diameter, participants' age, or the atherosclerotic burden of each patient. On the other hand, an anomalous origin of the VA and an abnormal entrance of the VA into the C6 TF are present at birth and do not change over time. Anomalous development of the VA is quite commonly accompanied by those of the adjacent bony structure such as an abnormal entrance of the vertebral artery not passing through the C6 TF [24-26]. Therefore, these characteristic

Table 3 Associations between an abnormal origin and an abnormal penetration of the VA into the transforamen

\begin{tabular}{lllll}
\hline & & \multicolumn{2}{l}{ MRA } & Total \\
\cline { 3 - 4 } & & V2 anomaly (+) & V2 anomaly (-) & \\
\hline CTA & V1 anomaly (+) & $8(1.7 \%)$ & $3(0.6 \%)$ & $11(2.3 \%)$ \\
& V1 anomaly (-) & $19(4.0 \%)$ & $446(93.7 \%)$ & $465(97.7 \%)$ \\
\multirow{2}{*}{ Total } & & $27(5.7 \%)$ & $449(94.3 \%)$ & $476(100 \%)$ \\
\hline
\end{tabular}

$P$ for chi-square $<0.001$

V1 VA with aortic origin in V1 segment, V2 VA with an abnormal entrance into the $\mathrm{C} 6$ transverse foramen 


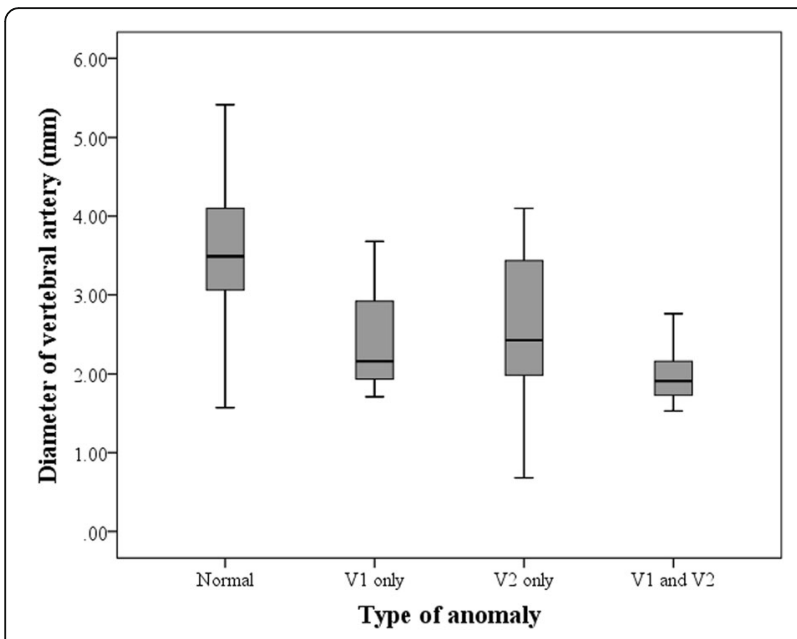

Fig. 2 Box plots showing the median and interquartile range values for the VA diameters. V1: VA with an aortic origin anomaly; V2: VA with an abnormal entrance into the transverse foramen

anomalies of the VA and the TF could be consistent markers for defining small or hypoplastic VA.

During embryological development, the VA develops from the longitudinal anastomosis of the intersegmental arteries [11, 12]. An abnormal development of the caudal portion of the intersegmental artery leads to the formation of a VA with an aortic origin which, in turn, may lead to an increased risk of developing VAH compared to a person with a normal VA [27, 28]. In an autopsy study, the prevalence of VAs with an aortic origin was reported to be $2-6 \%[14,29]$. A similar prevalence of VAs with an aortic origin was identified in the present study using MRA. Likewise, VAH is associated with the development of spontaneous VA dissection [30] and the present findings show that VAH was also closely related with the abnormal development or congenital vasculopathy of the VA.

Table 4 A linear mixed model analysis revealed associations between VA diameter and the clinico-anatomical characteristics of the patients

\begin{tabular}{llll}
\hline Predictor & $\mathrm{B}^{\mathrm{a}}(\mathrm{mm})$ & $95 \% \mathrm{Cl}$ & $P$ \\
\hline $\begin{array}{l}\text { Age, years } \\
\text { Female }^{\mathrm{b}}\end{array}$ & 0.0004 & $-0.005-0.006$ & 0.881 \\
Male & reference & & \\
Left VA $^{\mathrm{b}}$ & 0.174 & $0.033-0.315$ & 0.015 \\
Right VA $_{\text {V1 normal }}^{\mathrm{b}}$ & reference & & \\
V1 anomaly & -0.351 & $-0.484--0.217$ & $<0.001$ \\
V2 normal $^{\mathrm{b}}$ & reference & & \\
V2 anomaly $^{\text {aReference }}$ & reference & & $<0.001$ \\
b & -0.783 & $-1.112--0.454$ & $<0.001$ \\
\hline
\end{tabular}

${ }^{b}$ Estimates of fixed effects (VA diameter, $\mathrm{mm}$ )
A previous study of the association between the VA and the TF revealed a close relationship between the diameter of the TF and VA flow/diameter [19, 25, 26, 31]. Additionally, Hong et al. [19] reported that the incidence of an abnormal penetration of the VA into the TF (other than through C6) is approximately $5 \%$ and that the diameter of the TF significantly differs whether the VA passes through it or not. The present observations are in line with these previous findings. Taken together, these findings indicate that there is a close relationship between the VA and the TF.

In the present study, a linear mixed model analysis was used to estimate the diameter of the VA. A mixed model is a hierarchical model used to examine the associations among between-subject and within-subject variables [32]. As a rule, there are two VAs in the body, and the left VA tends to be larger than the right one. Therefore, a hierarchical linear mixed model is an optimal method to account for the repeated measures (two VAs) used in the present study. Additionally, patients with atretic or non-visualized VAs on vessel images were often excluded from the analyses of previous studies, which can lead to an underestimation of the prevalence of VAH because smaller arteries are more easily narrowed or occluded than larger ones $[3,4,6]$. Although atretic or non-visualized arteries are considered as a missing value, which in turn excluded in a traditional linear regression analysis, the mixed model can take account these missing data into the final statistical model [33]. Therefore, when using a linear mixed model, the data from patients with atretic or non-visualized VAs can be included in the estimation of VA diameter. Thus, in conjunction with the constant radiological characteristics of the VA anomalies, the use of a mixed model to assess the diameters of VAs strengthened the present results.

However, the present study has several limitations that must be considered. First, this study included only patients who were examined using CT and MR angiography simultaneously and this inclusion criterion may have led to an unintended selection bias. However, the proportions of comorbidities in the anomalous and nonanomalous VA groups did not differ significantly, particularly for patients with atherosclerotic diseases such as ischemic stroke. Second, although it is reasonable to assume that young patients would be included in the present study population based on the definition of $\mathrm{VAH}$ and there was an effort to focus on young patients free of cerebrovascular disease, a large number of older participants $(65.9 \pm 12.0$ years of age) were included in the present analyses. However, it is unreasonable to perform the CT angiography procedure on normal individuals to screen for VA diseases due to the hazards associated with the radiation and contrast agents.Finally, some stroke 
patients were included ( $n=107$ subjects) in this study. Because they are not all patient with posterior circulation infarct, we could not conclude the relationship between the VA anomalies and the occurrence of ischemic stroke. In addition, there is a sample size issue because small number of VA anomalies were not sufficient for subgroup analysis. Therefore, it is necessary to study whether the presence of vertebral artery variation is associated with the occurrence of posterior circulation stroke.

\section{Conclusion}

The present study demonstrated that the size of the VA was closely related with sex, laterality, and anomalies of the VA and that a linear mixed model was an optimal statistical method in assessing size of the VA.

\section{Additional file}

Additional file 1: Are the anomalous vertebral arteries more hypoplastic Raw data for the statistical analyses. Description of data: id, identification; gender; side (1: right, 2: left); V1, vertebral artery with an anomalous origin from the aorta (1: yes, 0 : no); V2, vertebral artery not passing through the 6th cervical transverse foramen (1: yes, 0 : no); Dia_VA, diameter of the vertebral artery (mm). (CSV $10 \mathrm{~kb})$

\section{Abbreviations}

PCS: Posterior circulation stroke; TF: Transverse foramen; VA: Vertebral artery; VAH: Vertebral artery hypoplasia

\section{Acknowledgements}

None.

\section{Funding}

The authors received a fund from Hallym Specialization Fund (No. HRF-S-53).

\section{Availability of data and materials}

We provided the datasets as Additional file 1 (csv format).

\section{Authors' contributions}

CK: data collection, study design, interpretation of the data, statistical analysis and drafting of the manuscript; JHS, study design, technical comments, interpretation of the data and drafting the manuscript; HCC: data collection, interpretation of the data. All the authors have read and approved the final manuscript.

\section{Ethics approval and consent to participate}

This study was approved by the Ethics Committee for the Chuncheon Sacred Heart Hospital (No. 2013-4). The study waived written informed consent because it was a retrospective data analysis.

\section{Consent for publication}

Not applicable.

\section{Competing interests}

The authors declare that they have no competing interests.

\section{Publisher's Note}

Springer Nature remains neutral with regard to jurisdictional claims in published maps and institutional affiliations.
Received: 18 April 2017 Accepted: 24 August 2017

Published online: 29 August 2017

\section{References}

1. Bogousslavsky J, Regli F, Maeder P, et al. The etiology of posterior circulation infarcts a prospective study using magnetic resonance imaging and magnetic resonance angiography. Neurology. 1993;43:1528-33.

2. Caplan L, Wityk R, Pazdera L, et al. New England Medical Center posterior circulation stroke registry II. Vascular lesions J Clin Neurol. 2005;1:31-49.

3. Park JH, Kim JM, Roh JK. Hypoplastic vertebral artery: frequency and associations with ischaemic stroke territory. J Neurol Neurosurg Psychiatry. 2007;78:954-8.

4. Chuang YM, Huang YC, Hu HH, et al. Toward a further elucidation: role of vertebral artery hypoplasia in acute ischemic stroke. Eur Neurol. 2005;55: $193-7$.

5. Perren F, Poglia D, Landis T, et al. Vertebral artery hypoplasia a predisposing factor for posterior circulation stroke? Neurology. 2007;68:65-7.

6. Chen YY, Chao AC, Hsu HY, et al. Vertebral artery hypoplasia is associated with a decrease in net vertebral flow volume. Ultrasound Med Biol. 2010;36: 38-43.

7. Jeng JS, Yip PK. Evaluation of vertebral artery hypoplasia and asymmetry by color-coded duplex ultrasonography. Ultrasound Med Biol. 2004;30:605-9.

8. Thierfelder KM, Baumann AB, Sommer WH, et al. Vertebral artery hypoplasia frequency and effect on cerebellar blood flow characteristics. Stroke. 2014; 45:1363-8.

9. Caldemeyer KS, Carrico JB, Mathews VP. The radiology and embryology of anomalous arteries of the head and neck. AJR Am J Roentgenol. 1998;170: 197-203.

10. Menshawi K, Mohr JP, Gutierrez J. A functional perspective on the embryology and anatomy of the cerebral blood supply. J Stroke. 2015;17: $144-58$

11. Padget $\mathrm{DH}$. The development of the cranial arteries in the human embryo. Contr Embryol. 1948:32:205-61.

12. Luh GY, Dean BL, Tomsick TA, et al. The persistent fetal carotidvertebrobasilar anastomoses. AJR Am J Roentgenol. 1999:172:1427-32.

13. Van Overbeeke JJ, Hillen B, Tulleken CA. A comparative study of the circle of Willis in fetal and adult life. The configuration of the posterior bifurcation of the posterior communicating artery. J Anat. 1991;176:45-54.

14. Sartor K, Freckmann N, Böker DK. Related anomalies of origin of left vertebral and left inferior thyroid arteries. Neuroradiology. 1980;19:27-30.

15. Vorster W, du Plooy PT, Meiring $\mathrm{JH}$. Abnormal origin of internal thoracic and vertebral arteries. Clin Anat. 1998:11:33-7.

16. Dudich $\mathrm{K}$, Bhadelia R, Srinivasan J. Anomalous vertebral artery origin may be an independent risk factor for arterial dissection. Eur J Neurol. 2005:12:571-2.

17. Uchino A, Saito $N$, Takahashi $M$, et al. Variations in the origin of the vertebral artery and its level of entry into the transverse foramen diagnosed by CT angiography. Neuroradiology. 2013;55:585-94.

18. Yi ZQ, Li L, Mo DP, et al. Anomalous vertebral artery not passing through the transverse foramen of the atlas. Chin Med J. 2009;122:2675-7.

19. Hong JT, Park DK, Lee MJ, et al. Anatomical variations of the vertebral artery segment in the lower cervical spine: analysis by three-dimensional computed tomography angiography. Spine. 2008;33:2422-6.

20. Cloud GC, Markus HS. Diagnosis and management of vertebral artery stenosis. QJM. 2003;96:27-54

21. Giannopoulos S, Markoula S, Kosmidou M, et al. Lateral medullary ischaemic events in young adults with hypoplastic vertebral artery. J Neurol Neurosurg Psychiatry. 2007;78:987-9.

22. Heiserman JE, Dean B, Hodak J, et al. Neurologic complications of cerebral angiography. AJNR Am J Neuroradiol. 1994:15:1401-7.

23. Sato K, Yoneya M, Otsuki A, et al. Anatomical vertebral artery hypoplasia and insufficiency impairs dynamic blood flow regulation. Clin Physiol Funct Imaging. 2015;35:485-9.

24. Meila D, Tysiac M, Petersen $M$, et al. Origin and course of the extracranial vertebral artery: CTA findings and embryologic considerations. Clin Neuroradiol. 2012;22:327-33

25. Kim C, Lee SH, Park SS, et al. A quantitative comparison of the vertebral artery and transverse foramen using CT angiography. J Clin Neurol. 2012;8: 259-64.

26. Sanelli PC, Tong S, Gonzalez RG, et al. Normal variation of vertebral artery on $C T$ angiography and its implications for diagnosis of acquired pathology. J Comput Assist Tomogr. 2002;26:462-70. 
27. Panicker HK, Tarnekar A, Dhawane V, et al. Anomalous origin of left vertebral artery-embryological basis and applied aspects-a case report. J Anat Soc India. 2002:51:234-5.

28. Mishra A, Pendharkar $\mathrm{H}$, Jayadaevan ER, et al. Anomalous origins of bilateral vertebral arteries in a child with down syndrome and Moyamoya disease. A case report. Interv Neuroradiol. 2012;18:259-63.

29. Lemke AJ, Benndorf G, Liebig T, et al. Anomalous origin of the right vertebral artery: review of the literature and case report of right vertebral artery origin distal to the left subclavian artery. AJNR Am J Neuroradiol. 1999;20:1318-21.

30. Zhou M, Zheng H, Gong S, et al. Vertebral artery hypoplasia and vertebral artery dissection a hospital-based cohort study. Neurology. 2015;84:818-24.

31. Kotil K, Kilincer C. Sizes of the transverse foramina correlate with blood flow and dominance of vertebral arteries. Spine J. 2014;14:933-7.

32. Edwards LJ. Modern statistical techniques for the analysis of longitudinal data in biomedical research. Pediatr Pulmonol. 2000;30:330-44.

33. Laird NM, Ware $\mathrm{JH}$. Random-effects models for longitudinal data. Biometrics. 1982;38:963-74.

Submit your next manuscript to BioMed Central and we will help you at every step:

- We accept pre-submission inquiries

- Our selector tool helps you to find the most relevant journal

- We provide round the clock customer support

- Convenient online submission

- Thorough peer review

- Inclusion in PubMed and all major indexing services

- Maximum visibility for your research

Submit your manuscript at www.biomedcentral.com/submit
Biomed Central 